\title{
(RE)PENSAR A DIMENSÃO CIENTÍFICA DO CONHECIMENTO.
}

\author{
José Barata-Moura ${ }^{1}$
}

\section{$\S$ 1. LANÇAMENTO.}

Agradeço à Universidade 11 de Novembro -- na pessoa do seu Reitor, Professor Doutor Kianvu Tamo -- a hospitalidade do acolhimento em Cabinda e o honroso convite para intervir nestas Jornadas, discursando na sua sessão inaugural.

Inaugurar significa abrir. E o pensamento é uma forma de abertura.

Quando pensamos, partimos de algo que parece "fechado", e damos-lhe voltas, para lhe surpreender aspectos e dimensões que, impensados, nos escapavam à atenção.

Vou, por isso, procurar pensar, perante vós, à minha maneira.

O orador que vem de fora é uma espécie de caixeiro-viajante. Desencantem-se, porém. Não trago, nos mostruários da bagagem, «novidades» assombrosas. Irei falar de coisas que todos vocês já sabem (e bem melhor do que eu).

Gostaria, no entanto, que a minha fala, ao ser posta em confronto com a vossa experiência e com a vossa reflexão, tivesse o efeito de um despertador: acordar para a feitura de um caminho pensante. Não apenas o meu, mas o nosso.

Foi-me proposto que, para um auditório especializado de investigadores e de docentes em diversos ramos do saber, me ocupasse da abordagem de um tema genérico: "(Re)pensar a dimensão científica do conhecimento".

Não sendo eu próprio especialista nestas matérias (nem porventura em nenhuma das outras sobre que me vou debruçando), aceitei de bom grado a encomenda. Muito em especial, pelo repto que ela nos lança.

Pensar - não fica mal, e até faz falta. Sobretudo, nos tempos que correm. Pelo menos, em Portugal, onde enxurradas de opinações (mediaticamente assistidas, sob o pontificado canoro do "achoquismo" solene) tendem a remover das vistas (e a deixar no desemprego) o pensamento (que na base delas pouco se encontra). Todos "acham que...", mas sem pensarem verdadeiramente "o quê".

Repensar - nem sempre dá jeito. É incómodo. Obriga a regressar ao exame de um conjunto de saberes, de que nos julgamos encartados detentores seguros. Reacende o levantamento de questões, que supúnhamos definitivamente resolvidas. Recoloca-nos em questão, no questionar que empreendemos. É uma maçada...

Ainda por cima, o enunciado do nosso tema não pergunta se nós transmitimos "conhecimentos", ou se os "conhecimentos" que nós transmitimos são "científicos" (o que desencadearia de imediato uma onda de respostas pela afirmativa). Quer-nos pôr a matutar sobre em que é que consiste afinal a cientificidade de um conhecimento. Uma caterva de barbicachos...

Os filósofos são mesmo uns tipos retorcidos. Enrodilhados. Um atraso de vida. Perante um qualquer problema que se apresente, têm sempre a desgraçada mania de pôr logo a funcionar aquele aparelho esquisito que dá pelo nome de "complicómetro"...

E, no entanto, talvez seja aconselhável não despedir precipitadamente o pensar, nem mandá-lo de licença graciosa para uns banhos na praia. 
No fundo, o que nós gostávamos é que tudo fosse tão simples, tão simples, que o pudéssemos captar imediatamente num instante de resplendor, numa intuição radiosa, num repente de sapiência infusa.

Ou então, gostávamos que tudo fosse tão complicado, tão complicado, ao ponto de se tornar impenetrável, inatingível, de se converter num mero objecto de crença que, sem mais razões, por súbita adesão sentimental se adopta.

Mas não é bem assim.

As coisas só são "simples", avistadas de longe. Quando nós não entramos nelas. Quando ficamos "de fora", à porta.

E a "complicação" também não é um letreiro de afugento, a dizer: passagem proibida, mata cerrada, beco sem saída.

Daí a tensão, e o transtorno. Daí o mal-estar. Daí o desafio.

Tornar uma coisa "inteligível", descortinando-lhe os sentidos (aqueles que em próprio possui, e os que lhe são atribuídos), veícula e vincula um esforço para penetrar nela, e nas suas molduras de enquadramento. Remete, incontornavelmente, para um trabalho (pensante) de lida com a complexidade do real.

E toda a "aventura do conhecimento" tem precisamente a ver com isto: com a demanda de uma inteligibilidade que se busca.

Este é o problema que o nosso tema nos propõe, nos coloca pela frente.

Dêmos corda aos sapatos de pensar. Partamos à viagem.

Sabendo que, nas contemporâneas sociedades de uma sofisticada tecnologia em rede, há decerto espaçosas "auto-estradas" (highways) por onde o tráfego da informação circula ${ }^{2}$. Mas que, em todo o caso, continuaremos a não ter à disposição -- seguindo uma metáfora rodoviária (com pergaminhos seculares) -- nem uma "estrada militar" (Heeresstraße) ${ }^{3}$, nem um "caminho real" (route royale $)^{4}$, para a ciência.

Pela própria natureza intrínseca de que se reveste -- tirando partido dos cabedais de saber acumulados, e dos avanços entretanto ocorridos nos instrumentos de pesquisa e de comunicação --, em qualquer domínio, um conhecimento científico tem sempre que ser produzido, apropriado, e feito medrar. Pensando.

A ciência só acontece, porque se faz.

\section{$\S 2$. CONHECER.}

Comecemos pelo conhecer.

Aparentemente, com maior ou menor dose de bisbilhotice atrelada, é aonde toda a gente quer chegar.

Ficou famosa a primeira linha da Metafísica de Aristóteles: " $\mathrm{B} \varsigma<\vartheta \gamma \mathrm{H} \square<2 \Delta \mathrm{TB} \cong 4$ $\cong \simeq$ $\gamma \varnothing * \Xi<\forall 4 \notin \Delta \Xi(\cong<\vartheta \forall 4 \mathrm{~N} \beta \Phi \gamma 4$ ”, 5 , "por natureza, todos os homens aspiram ao saber", ou a ter uma ideia das coisas. Mas também houve formas de religiosidade orientalizante em que o ideal da sabedoria - por vezes, popularmente simbolizado na representação dos três macacos que tapam olhos, ouvidos, e boca - era colocado na ignorância e no apartamento relativamente à maldade das coisas do mundo. Mesmo na nossa cultura, a "curiosidade" (curiositas) não deixou de estar inscrita no extenso "rol dos pecados", sendo castigada como um ímpio assomo de indiscreta concupiscência ${ }^{6}$. E, infelizmente, continua a ser comum mandar-se calar as crianças que perguntam em demasia. 
Aparentemente, e numa acepção trivial, "conhecer" é também aquilo que toda a gente já sabe o que é.

Uma pessoa que nunca vimos: não conhecemos. Se toparmos com o sujeito um par de vezes, na rua ou no café, o estatuto muda: passa logo a ser "um conhecido" (de vista). Uma coisa de que nunca ouvimos falar: não conhecemos. Mas também todos "conhecemos" coisas apenas porque nos contaram, porque ouvimos dizer.

Normalmente, sentimos "conhecer" aquilo a que estamos "acostumados", aquilo que, de alguma maneira, "mora" na, ou se "passeia" pela, esfera das convivências que é usual frequentarmos.

É o chamado «conhecimento» por "contacto directo", ou "de proximidade". Em concepções de inspiração anglo-saxónica que recorrem a um figurino terminológico de origem russelliana, diz-se: knowledge by acquaintance ${ }^{7}$.

Admitimos, muitas vezes, como "conhecido" algo que afinal tão-só faz parte de uma paisagem que nos é "familiar". Estamos convencidos por hábito de que uma coisa é assim, e não nos atardamos com mais perguntas.

Razão de sobra tinha Hegel, quando, a propósito de debates desta índole (que no tempo dele também ocorriam), tratava de insistir em que "aquilo que é familiar" (das Bekannte) não se torna, por esse facto, automaticamente "conhecido" (erkannt) ${ }^{8}$. Falta-lhe, designadamente, uma componente decisiva: o trabalho daquela mediação pensante que lhe percorre os meandros e manifesta o conteúdo.

Lembremos alguns termos genéricos de enquadramento.

Conhecer algo envolve uma objectivação: o tomar de uma certa "distância" que, em simultâneo, não obstante "re-une". Supõe a separação desse algo relativamente a um plano de fundo do qual se recorta, para que venha a poder tornar-se objecto de interesse. No grego antigo -- e, em especial (enquanto filosofema), no vocabulário de Sócrates e de Platão --, $2 \gamma \mathrm{T} \Delta \therefore \forall$ significava "contemplação" " : aquele mirar atento de um ob-jecto que, dando-se ao espectáculo, se mostra.

Conhecer con-cita um relacionamento. Não é uma dualidade estanque de entes contrapostos. Verifica-se uma acção recíproca (diferenciada) entre as instâncias em presença. É neste sentido que na versão grega da Bíblia, preparada em Alexandria pelos Setenta, se recorreu ao verbo $(4(<\phi \Phi 6 \mathrm{~T}$ (conhecer) para traduzir o consumar do comércio carnal, o caraa-cara desnudado em que uma parelha tem "relações sexuais"10.

E o conhecer desprende-se ainda de uma repetição de encontros experimentados, que a memória retém ${ }^{11}$. Não brota de um momento único. Forma-se no decorrer de um processo, em que «o mesmo», ou algo de "semelhante", através de variações ligeiras e de provas congruentes, se comprova. O escultor "conhece" a pedra, porque a afeiçoa; o carpinteiro «conhece» as madeiras, porque se serve delas no seu artesanato.

Por outro lado, é sempre muito diferente conhecer por experiência (o que supõe uma habituação activa e pensada no confronto com a realidade), ou saber apenas pelos livros (através da autoridade informativa que eles indirectamente proporcionam), ou imaginar que as palranças do papagaio amestrado (com a sua recitação de uns fraseados à pressa aprendidos de cor) constituem um certificado autêntico de sabença ${ }^{12}$.

Entretanto, o conhecer inegavelmente também se enriquece quando, no âmbito de uma experiência que se aprofunda e desenvolve, lançando mão de um instrumentário aperfeiçoado, somos capazes de descrever com acuidade (o que se passa), ou de medir com rigor (o que se dá), ou de analisar com critério (decompondo os vários elementos que integram um todo). Muitas correntes epistemológicas se organizaram, e organizam, em torno da prevalência de 
cada um destes eixos: da fenomenologia husserliana ${ }^{13}$ aos analiticismos de matriz vienense ${ }^{14}$, do acantonamento oitocentista nas perspectivas da "descrição" (Beschreibung) ${ }^{15}$ até às mais recentes magnificações da métrica ${ }^{16}$.

São importantes dimensões atendíveis. Têm um papel a desempenhar.

Mas, em rigor, a chave para o conhecer abre portas num outro patamar, uma vez que releva das tarefas da com-preensão.

Compreender não é apenas inserir as torrentes do "dado" numa fluxão unificada de "vivências" (Erlebnisse) 17, ou alimentar no interior da "duração" (durée) uma certa "camaradagem" (camaraderie) com os "vividos" (vécus) ${ }^{18}$. Compreender não é tão-só acolher aquilo que se dá, assentir, e interpretar, seguindo os estudados preceitos da arte hermenêutica 19. Compreender envolve - recordando uma categoria hegeliana ${ }^{20}$, que dos naufrágios no idealismo Marx não deixou de recuperar, em regime materialista ${ }^{21}{ }_{--}$uma elevação à perspectiva totalizante do "conceito" (Begriff).

Para compreender, precisamos de conseguir articular dialecticamente o uno e o múltiplo. Perceber, na unidade do objecto, a multiplicidade de aspectos que incorpora. Perceber, na multiplicidade dos elementos, as unidades que eles consubstanciam. Não apenas na ordem estática de uma apresentação, eventualmente justaposta. Mas também na vertente dinâmica da sua deveniência e da sua transformação.

É, no fundo, pelo carreiro destes trilhos que começa a desenhar-se-nos a via para o necessário ponderamento da dimensão científica do conhecer.

\section{§ 3. A FORMA CIENTÍFICA.}

Nem todos os conhecimentos que possuímos são tematizados como tal. Todos os conhecimentos reflectem algo (na forma subjectiva que lhes é própria), mas nem todos eles são alvo de uma re-flexão pensante. Podem apresentar-se como meramente tácitos ${ }^{22}$ ou funcionais, limitando-se a suportar uma acção que se leva a cabo.

Todo o pensar - na medida em que tem objecto - aponta a algum conhecimento. Mesmo quando se solta na figura do devaneio intimista, ou quando deliberadamente se plasma nos ideatos criativos da ficção (como acontece com a Arte).

Mas nem todos os conhecimentos dispõem de forma científica.

Volta a complicação pegada.

Pode haver perguntas simples. Mas a simplicidade não é apanágio da resposta a problemas complexos. E não é porque nós sejamos particularmente "implicativos" na utilização que damos ao besunto do bestunto. É porque a realidade se tece e entretece de complexidades, que, ainda por cima, se transformam.

Muitas vezes, grassa o costume de se exibir a qualificação de "científico" como uma espécie de antecipado selo de garantia para qualquer produto oriundo de uma certa região demarcada, ou como um expediente liminar para rapidamente varrer da praça a concorrência julgada incómoda. Isto ou aquilo é "científico", aqueloutro não é; e o veredicto basta para ficarmos contentes, porque não se questiona mais ${ }^{23}$.

Outras vezes, imagina-se que a cientificidade resulta, sem mais, de se aplicarem as técnicas do ofício (não raro, baptizadas de "metodologia"). Ler o breviário, seguir o manual de procedimentos, observar o código das "boas práticas", pôr cruzinhas na folha de controlo, trariam como prémio «a ciência». Ponto final. Esquece-se que o método (mesmo na sua formalidade) é indissociável da própria natureza do objecto em apreço ${ }^{24}$.

Em situações de maior aperto, e de menor clarividência no manejo da dialéctica, alegase que é "ciência" aquilo que a comunidade científica respectiva (e, sobretudo o main stream, 
ou a moda que está a dar) entende, no preceito das suas consensualizações, que é "ciência" 25. E torna a fazer-se uma poupança nas interrogações fundamentais.

Diziam os escolásticos, no seguimento de uma larga tradição aristotélica ${ }^{26}$, que só há ciência do "geral". Porque as coisas na sua singularidade variam muito, e só algo com as propriedades do "universal" está em condições de fornecer aquele quadro de permanência e de imutabilidade ${ }^{27}$ que permite um conhecimento que não fuja ${ }^{28}$. Foi ainda sobre este paradigma matricial, entretanto transformado (e sujeito a controvérsias de monta, designadamente, no tocante ao fundamento da necessidade), que se veio a construir a concepção moderna da lei, entendida como reflectindo a vigência de relações constantes entre fenómenos da Natureza ${ }^{29}$ (desejavelmente, susceptíveis de expressão matematizada) ${ }^{30}$. E se a realidade teima em mudar mesmo, mostrando-se rebarbativa ao enfaixamento em certas domesticações, logo outros acrescentaram que, então o melhor seria restringir a ciência a um estudo de "modelos" -- umas "ficções esquemáticas" (schematische Fiktionen) úteis ${ }^{31}$, como Vaihinger os designou --, porque aí podemos mais convenientemente controlar as diferentes variáveis no seu isolamento.

A ciência visa, por certo, o apuramento da verdade. Mas talvez seja de não confundir a verdade com a correcção de um enunciado (que reflecte adequadamente um determinado estado-de-coisas imediato) ${ }^{32}$, ou com a certeza subjectiva de que se dispõe para as afirmações ${ }^{33}$. Como (apesar de toda a bateria de supostos idealistas em que o seu pensamento assenta) Hegel não deixou de observar com justeza, «o verdadeiro é o todo» (das Wahre ist das Ganze), porque o real, na concreção do processo em que con-siste, não se circunscreve à imediatez rígida das suas apresentações e representações ${ }^{34}$.

Por sua vez, Marx, no Livro terceiro de $O$ Capital, pôs em destaque um ponto de epistemologia que merece atenção. Se "a forma fenomênica" (die Erscheinungsform) - aquilo que na experiência sensível de pronto aparece - coincidisse "imediatamente" (unmittelbar) com "a essência das coisas" (das Wesen der Dinge), então, "toda a ciência" (alle Wissenschaft) se tornaria "supérflua" (überflüssig) ${ }^{35}$.

Isto é, não basta cingirmo-nos à facticidade positiva daquilo que se dá, e que nos está diante. É preciso investigar "a conexão" (der Zusammenhang) que entrelaça -- nas formas, e nos supostos, do seu devir -- tudo aquilo que se manifesta.

E, porque a "essência" (enquanto figura de um princípio de inteligibilidade que se demanda) não se encontra fora do real - acima dele (numa instância transcendente), ou ao lado dele (num plano lógico-transcendental), mas na materialidade da sua própria estruturação interna --, é preciso perguntar pela razão de ser das coisas, das relações, dos processos ${ }^{36}$.

Heraclito havia denominado essa estrutura una, que articula e rege o múltiplo nas suas oposições e diferenças: "razão" (8 $\left(\cong \mathrm{H},(<\phi: 0){ }^{37}\right.$. E Platão, no marco da sua doutrina da

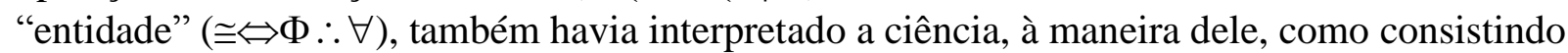
num $8 \overline{(\cong}<* 4 * \overline{<} \forall 4$, num "dar razão", susceptível de mostrar o fundamento de "aquilo que é" $(\vartheta \in \angle<){ }^{38}$.

$\mathrm{Na}$ verdade, aquilo que se procura como ciência ( $f \mathrm{~B} 4 \Phi$ ЭZ:0, Wissenschaft) é um saber fundamentado. Isto é, um saber que concebe o seu objecto na relação reticular que ele guarda com o conjunto deveniente das determinações que integra, com os supostos em que assenta, e que lhe comandam os movimentos. As exigências de racionalidade e de sistemicidade $^{39}$ é deste, e sobre este, solo que se elevam.

A busca do fundamento real é, por isso, constitutiva de toda a atitude científica. Mesmo quando lhe cabe investigar aquele horizonte subjectivo, e inter-subjectivo, de relações que incontornavelmente enlaça (e afecta) a dialéctica de sujeito e de objecto ${ }^{40}$. Mesmo quando não pretende, ou não consegue, livrar-se de uma embaraçante tralha de andaimes idealistas para edificar a sua epistemologia ${ }^{41}$. 
Mas a forma científica não é a mesma em todos os domínios do saber humano ${ }^{42}$, nem em todos os estádios do desenvolvimento humano ${ }^{43}$.

A unidade do real não é uniformidade, nem mono-tonia. A realidade, múltipla nas suas arquitecturas, transforma-se, e, com ela, o nosso saber científico igualmente se transforma.

Não se trata de genuflexão ante aquele "relativismo" (simplório, ou sofisticado) do "vale tudo o mesmo" 44 , porque tudo se equivale. Trata-se da historicidade intrínseca de uma condição ontológica de relatividade (subjectiva, e objectiva), em que se impõe perguntar (dialecticamente) pelo fundamento (material) de tudo aquilo que vale.

Só por isso, não escasseiam de todo os motivos para tempestivamente (re)pensar a dimensão científica do conhecimento.

E, para inquirir de um saber fundamentado, em qualquer domínio do interesse, é preciso proceder a uma activação do pensar.

\section{$\S 4$. ALGUNS TRAÇOS DO PENSAR.}

A ciência não se faz apenas com pensamentos, ou sobre pensamentos (como se estes fossem a realização per-feita do ser ${ }^{45}$, ou um sucedâneo imediatamente sensível do real a cuja análise a ciência se reduz ${ }^{46}$ ). Mas não há saber científico, em nenhum dos seus ramos, sem a mobilização de um pensar ${ }^{47}$.

Abalançando-me a pular para uma sistematização rápida -- sendo o salto talvez desmesurado, por ausência de necessárias mediações explicitadas --, pergunto:

Que traços poderíamos nós distinguir neste pensar, que é requerido (e que muita falta faz)?

Limito-me, em esboço quase telegráfico, à indicação de umas quatro direcções principais:

radicalidade crítica;

procura de fundamentação;

cuidado pelo estabelecimento dos problemas;

desdobramento e exploração do leque dos possíveis.

Vejamos algo acerca de cada uma delas.

Criticar não é dizer mal; é procurar ver bem.

Criticar não é contra-pôr a um enunciado unilateral dado outras abstracções que se debitam, e que o contrariam; é tentar pôr o emaranhado dos processos, recheados de contradições, na articulada concreção deveniente que formam.

Criticar não é, perante a ruindade constatada das envolvências do quotidiano, partir em nobre e exaltante expedição para os normativos de um "dever-ser" idealizado; é mergulhar na espessura conturbada do "ser", para lhe discernir a negatividade que internamente o trabalha.

A crítica corresponde à exigente actividade de um exame racional, interactivo e polifónico, que ao nível dos supostos se exerce e desenvolve. São estas camadas mais profundas que constituem propriamente o campo de incidência da crítica.

E, por conseguinte, para lhe surpreender o terreno em que é chamada a mover-se, há que ir em busca de um plano fundante.

A ciência não é uma poltrona confortável. Para merecido descanso dos exaustos. E para o controlo remoto das operações, deslocando o manípulo nas consolas. 
A ciência não é a fundamentação; é a procura do fundamento. Remontando para aquém daquilo que na imediatez da sua positividade se impõe (ou nos é imposto). Indo à sondagem dos alicerces em que o que aparece como instalado e "evidente" se firma. Procurando surpreender na sua latência a dinâmica tendencial que, a um tempo, insinua e esconde.

Buscar a fundamentação é, portanto, intentar com-preender, nas suas raízes e no seu desenvolvimento, algo que, de pronto, se nos fenomenaliza como fixado aí, como uma "facticidade" desprovida de génese e sem por vir.

Com o aprofundamento da pesquisa, e ao invés do que de ordinário parece ser admitido, verifica-se que epistemologia e ontologia, na diferença das intenções formais respectivas, partilham, no limite, um mesmo território de implantação.

Porque toda a "tese" ou "posição" é função concreta de uma problemática que se descobre e constrói, importa cuidar especialmente do estabelecimento dos problemas. Isto é, daquele complexo multideterminado, e deveniente, sobre cujo fundo se desenham e emergem os diversos, os contrários, os conflituantes.

Uma vez mais, trata-se de investigar aquilo que suporta ou sustenta enunciados, proposições, "factos", no sentido de lhes desvendar, não tanto genealogias lineares de condicionamento e de causação, mas o entramado dinâmico (no limite: contraditório) de determinações, de vectores, e de processos, que os subtende e organiza.

O trabalho do pensar não olha apenas para as respostas (as quais também não vêm num súbito raio de luz, nem caem de paraquedas do céu); começa, mais cedo, com a criteriosa elaboração dos questionários, que lhes definem o horizonte e os contornos do encontro.

O ser pelo qual perguntamos - porque nos confronta e nos investe, porque nele estamos implantados como ingrediência e como agência - não se reduz nem aos entes discretos que formam o múltiplo, nem às essencialidades unas que os estruturam.

$O$ real não se circunscreve ao existente, nem àquilo de que temos notícia como acontecido. Por isso, é tarefa constitutiva do pensar, que na sua radicalidade se exerça, empreender também uma sondagem e uma exploração do leque de possibilidades reais (materialmente fundadas, mesmo quando subjectivamente operadas) que cada existência comporta e adiante de si pro-jecta.

O pensar, nele próprio, é, em última (ou em primeira) instância, um elaborado processo de demanda da inteligibilidade. Mas, até naquelas deambulações em que mais parece absorto em distendidos exercícios de sobrevoo planado, o pensar é sempre uma função vital. Está montado sobre, e voltado para, a processualidade mundana do real, onde o viver dos seres humanos materialmente se inscreve.

Sem um fundo envolvimento do pensar, não há constituição de saber científico.

A teoria, quando correcta, reflecte adequadamente o ser, na sua concreção e nas suas dinâmicas.

Mas a teoria, mesmo quando correcta, não esgota, não substitui, não dispensa, a transbordante riqueza das realidades em efervescência, que (à nossa volta, e connosco) prosseguem o curso histórico da sua marcha.

Mais outra atrapalhação a complicar-nos o passo...

\section{$\S$ 5. REMATE.}

Porque a voz do contraditório tarda, e a outros cabe expôr fazendas de mais fina qualidade, é tempo de concluir esta fala, que já vai longa e aborrecente. 
Repensar a dimensão científica do conhecimento não é um curioso entretém para os vagares do ócio. Faz parte da medula do negócio. Permite redescobrir e reconfigurar sentidos ao trabalho de que, em diferentes áreas do saber, fazemos profissão.

Para aqueles que se revelem mais atreitos a uma entrega às delícias da divagação meditabunda, sem dúvida que o pensar aconchega.

Só que pensar, simplesmente, não chega.

O interpelante desafio que em permanência se nos abre é a procura de chegar a formas de saber fundamentado. Investigando, debatendo, transmitindo. É por isso que as Universidades justificadamente inscrevem, no elenco das suas missões estruturantes, a ocupação com um cultivo científico dos saberes ${ }^{48}$.

Emprego deliberadamente "cultivo", no intuito de fazer ressaltar aqui um vector nevrálgico para a própria concepção da cultura.

Ao contrário do que habitualmente muitos sentenciam, a cultura não se limita a reflectir, a pôr em perspectiva, e a fornecer de quando em vez o verniz de uns delicados arranjos florais a título de ornamento.

Cultura não é apenas inventário, conservatório, e difusão. É, fundamentalmente, cultivo. Acrescento de valor a uma cadeia de valores sedimentados que se retrabalham.

Pela sua vivificação como cultivo, a cultura devém uma polifacetada lavrança das realidades. Para, tomando criticamente a cargo aquele património que nos entregam, as compreender, e trans-formar.

E os enrocamentos, e enroscamentos, tornam a emergir.

Por si só, a teoria não transforma.

Falta mão à obra que a cabeça idealiza.

No entanto, em regime de absoluto divórcio relativamente a um saber provido de fundamento, também não há transformação efectiva que ganhe pé: com consistência no teor, e consequência nos desenlaces.

Daí, aquela exigência tremenda (não apenas ética) ${ }^{49}$, que nos rasga os horizontes da nossa responsabilidade: de universitários, de cidadãos, de seres humanos.

Poderia, porventura, retratar-se no seguinte lema:

Compreender transformando; transformar compreendendo.

Num certo sentido, todos nós - nos grandes actos de que fica registo, bem como na modéstia dos quotidianos por onde vamos vivendo -- somos num des-equilíbrio rumo ao futuro.

Porque o futuro é um feituro: um a fazer por fazer.

Possa aquele saber que em forma científica buscamos trazer luz à feitura de um mundo que esteja à altura das possibilidades reais do estado do nosso desenvolvimento, e dos enriquecidos padrões de humanidade que nos cumpre nele ir inscrevendo.

Não é um voto piedoso para devotas obras pias em espera.

É o incitamento crítico a uma esperança trabalhada.

Muito obrigado pela generosa paciência da vossa atenção.

Lisboa, Agosto de 2013. 
(Conferência inaugural da "Primeira Semana Epistemológica", proferida em 25 de Setembro de 2013, na Universidade 11 de Novembro - Cabinda, Angola).

\begin{abstract}
${ }^{1}$ Professor Catedrático do Departamento de Filosofia da Faculdade de Letras da Universidade de Lisboa. VicePresidente da Internationale Gesellschaft Hegel-Marx für dialektisches Denken. Deputado ao Parlamento Europeu (1993-1994). Reitor da Universidade de Lisboa (1998-2006). Membro do Conselho Nacional de Avaliação do Ensino Superior (1999-2006). Membro do Conselho Nacional de Educação (2007-2011). Sócio correspondente da Academia Internacional da Cultura Portuguesa. Sócio efectivo da Academia das Ciências de Lisboa.
\end{abstract}

${ }^{2}$ Veja-se, por exemplo, Manuel CASTELLS, The Information Age: Economy, Society and Culture (1996-1998), Malden - Oxford - Carlton, Blackwell Publishing, 2000², 3 vols.

${ }^{3}$ Cf. Immanuel KANT, Kritik der reinen Vernunft (1781), Transzendentale Methodenlehre, 4; A 856, B 884.

${ }^{4}$ Cf. Karl MARX, Lettre au citoyen Maurice La Châtre, 18 Mars 1872; Marx-Engels Gesamtausgabe, ed. Günter Heyden e Georgi Smirnow (doravante: MEGA2), Berlin, Dietz Verlag, 1989, vol. II/7, p. 9.

${ }^{5}$ ARISTÓTELES, Metafísica, A, 1, 980 a 21.

${ }^{6}$ Veja-se, por exemplo, Aurélio AGOSTINHO, Confessionum libri tredecim, V, 3, 4; X, 35, 55; etc. Para outros desenvolvimentos: Hans BLUMENBERG, Die Legitimität der Neuzeit. Erneuerte Ausgabe, III, VI; Frankfurt am Main, Suhrkamp Verlag, 1996, pp. 358-376.

${ }^{7}$ Como texto clássico de referência: Bertrand RUSSELL, "Knowledge by Acquaintance and Knowledge by Description", The Problems of Philosophy (1912), 5; London - Oxford - New York, Oxford University Press, $1973^{3}$, pp. $25-32$.

8 "Habitualmente" (gewöhnlich), esse apenas por familiaridade "conhecido" acaba até por se revelar como "o mais desconhecido" (das Unbekannteste). Cf. Georg Wilhelm Friedrich HEGEL, Enzyklopädie der philosophischen Wissenschaften im Grundrisse (1830), § 24, Zusatz 2; Theorie Werkausgabe, red. Eva Moldenhauer e Karl Markus Michel (doravante: TW), Frankfurt am Main, Suhrkamp Verlag, 1970, vol. 8, p. 85. Observações indo neste mesmo sentido são, aliás, recorrentes nos escritos hegelianos. Veja-se: HEGEL, Phänomenologie des Geistes, Vorrede (TW, vol. 3, p. 35); Wissenschaft der Logik, Vorrede zur zweiten Ausgabe (TW, vol. 5, p. 22); Vorlesungen über die Geschichte der Philosophie, Einleitung, A, 2, a (TW, vol. 18, p. 39).

${ }^{9}$ Veja-se, por exemplo: PLATÃO, República, VII, 529 b.

${ }^{10}$ De passagem, será interessante observar, no jogo das metáforas gnosiológicas que são feitas intervir, o trânsito que conduz do "conhecimento" ao "conceito": "Adão conheceu Eva, sua mulher. Ela concebeu, e deu à luz Caim”, Génesis, 4, 1.

${ }^{11}$ Para duas associações emblemáticas da «repetição» e da «memória» ao entendimento de aquilo em que a «experiência» consiste, vejam-se, por exemplo: ARISTÓTELES, Metafísica, A, 1, 980 b 28 - 981 a 1, e Thomas HOBBES, Leviathan, or The Matter, Forme \& Power of a Common-Wealth Eclesiasticall and Civill (1651), I, 2; ed. Crawford Brough Macpherson, Harmondsworth, Penguin Books, $1980^{10}$, p. 89.

\footnotetext{
${ }^{12}$ Ante a embevecida predilecção de certos pedagogismos escolásticos pelo culto da "ciência" vomitiva, apenas papagueada e "indigerida", já Montaigne disparava num comentário sarcástico:

"É testemunho de grosseria e de indigestão regorgitar a vianda tal como se engoliu." -- "C'est témoignage de crudité et d'indigestion que de regorger la viande comme on l'a avalée.”, Michel Eyquem de MONTAIGNE, Essais (1580), I, 26; Oeuvres Complètes, ed. Robert Barral, Paris, Éditions du Seuil, 1967, p. 74.
}

${ }^{13}$ Cf. Edmund HUSSERL, Ideen zu einer reinen Phänomenologie und phänomenologischen Philosophie. Erstes Buch: Allgemeine Einführung in die reine Phänomenologie (1913), III, 1, §§ 73-75; Halle, Verlag von Max Niemeyer, $1928^{3}$, pp. 136-141.

${ }^{14}$ Vejam-se, por exemplo: Rudolf CARNAP, "Überwindung der Metaphysik durch logische Analyse der Sprache", Erkenntnis, Leipzig - den Haag, II (1932), pp. 219-241, e Alfred Julius AYER, The Central Questions of Philosophy (1973), III; Harmondsworth, Penguin Books, $1978^{4}$, pp. 44-67. 


\begin{abstract}
${ }^{15}$ Para um enquadramento das diferentes ocorrências, e uma aclaração dos seus contextos polémicos, vejam-se, por exemplo: Friedrich KAULBACH, Philosophie der Beschreibung, Köln - Graz, Böhlau, 1968; Ferdinand FELLMANN, «Wissenschaft als Beschreibung», Archiv für Begriffsgeschichte, Bonn, 18 (1974), pp. 227-261; e Ferdinando VIDONI, Ignorabimus! Emil Du Bois-Reymond und die Debatte über die Grenzen wissenschaftlicher Erkenntnis im 19. Jahrhundert, Frankfurt am Main - Bern - New York - Paris, Verlag Peter Lang, 1991.
\end{abstract}

${ }^{16}$ Para uma informação breve acerca dos desenvolvimentos na modelização econométrica, veja-se, por exemplo: John Kenneth GALBRAITH, A History of Economics. The Past as the Present (1987), XIX; London, Penguin Books, $1991^{3}$, pp. 261-265.

${ }^{17}$ Cf. Wilhelm DILTHEY, Leben und Erkennen (1892-1893); Gesammelte Schriften, ed. Helmut Johach e Frithjof Rodi, Göttingen, Vandenhhoeck \& Ruprecht, 1982, vol. 19, pp. 359-388.

${ }^{18}$ Cf. Henri BERGSON, Introduction à la Métaphysique (1903), La Pensée et le Mouvant. Essais et Conférences (1934), VI; Oeuvres (Èdition du Centenaire), ed. André Robinet, Paris, Presses Universitaires de France, $1963^{2}$, pp. 1392-1432.

${ }^{19}$ Cf. Friedrich SCHLEIERMACHER, Hermeneutik und Kritik, mit besonderer Beziehung auf das Neue Testament (1838); ed. Manfred Frank, Frankfurt am Main, Suhrkamp Verlag, 19935; Hans-Georg GADAMER, Wahrheit und Methode. Grundzüge einer philosophischen Hermeneutik (1960), Tübingen, J. C. B. Mohr (Paul Siebeck), 1975 ; Paul RICOEUR, Le conflit des interprétations. Essais d'hermeneutique, Paris, Éditions du Seuil, 1969 ; etc

${ }^{20} \mathrm{O}$ “conceito" pode sem dúvida ser em abstracto tomado como uma "abreviatura" (Abbreviatur), como uma "fórmula" (Formel); mas, segundo o léxico categorial do idealismo objectivo hegeliano, ele pretende significar uma totalidade real concreta de determinações em devir. Cf. HEGEL, Wissenschaft der Logik, Vorrede zur zweiten Ausgabe, e II, II, 1; TW, respectivamente, vol. 5, pp. 19-34 e vol. 6, pp. 273-301.

A despeito da ambiguidade ontológica, é neste sentido que «o próprio conhecimento não é nada mais do que o desenvolvimento do conceito» -- "die Erkenntnis selbst ist nichts als die Entwicklung des Begriffs", HEGEL, Vorlesungen über die Philosophie der Religion, Einleitung, C, I; TW, vol. 16, p. 66.

${ }^{21} \mathrm{Na}$ intencionalidade visada, o endereço combativo é claro, e foi amplamente glosado: “Os filósofos têm apenas interpretado o mundo de modos diversos; trate-se de o transformar." - "Die Philosophen haben die Welt nur verschieden interpretiert, es kömmt drauf an, sie zu verändern.”, MARX, Thesen über Feuerbach, 11; MarxEngels Werke, ed. IML (doravante: MEW), Berlin, Dietz Verlag, 1976 ${ }^{5}$, vol. 3, p. 7.

No entanto, em ordem ao correcto entendimento da doutrina, e à prevenção de alguns apressados licenciamentos da teoria (que, por vezes, afloram), será indispensável ter em conta algo que anteriormente foi explicitado: «Toda a vida social é essencialmente prática. Todos os mistérios que levam a teoria ao misticismo encontram a sua solução racional na prática humana e no conceber [Begreifen] dessa prática." - "Alles gesellschaftliche Leben ist wesentlich praktisch. Alle Mysterien, welche die Theorie zum Mystizism veranlassen, finden ihre rationelle Lösung in der menschlichen Praxis und in dem Begreifen dieser Praxis.”, MARX, Thesen über Feuerbach, 8; MEW, vol. 3, p. 7.

A compreensão não basta, mas para revolucionar é preciso compreender O que supõe uma inscrição no horizonte do "conceito". Daí os repetidos alertas contra a tacanhez daquela pretensa crítica "que sabe julgar e condenar o presente, mas não o [sabe] conceber" - "welche die Gegenwart zu be- und verurtheilen, aber nicht zu begreifen weiß”, MARX, Das Kapital. Kritik der politischen Ökonomie. Erster Band. Hamburg 1867, I, IV, 4; MEGA², vol. II/5, p. 410.

${ }^{22}$ Não emprego aqui o adjectivo na acepção que ele adquire nas concepções (ao debate de cujos supostos haveria que proceder) de Michael POLANYI, The Tacit Dimension, Garden City (New York), Doubleday \& Company, 1966.

${ }^{23}$ Por vezes, é nesta direcção que vai a leitura simplificada que se faz de obras como: Karl Raimund POPPER, Conjectures and Refutations. The Growth of Scientific Knowledge (1962), London - New York, Routledge Classics, 2006 ${ }^{9}$, ou Objective Knowledge, Oxford, Clarendon Press, 1972; Ernst TOPITSCH, Sozialphilosophie zwischen Ideologie und Wissenschaft (1961), Neuwied am Rhein - Berlin, Hermann Luchterhand Verlag, 1971 ${ }^{3}$; Louis ALTHUSSER, Philosophie et Philosophie Spontanée des Savants (1967), Paris, François Maspero, 1974; etc.

Os problemas fronteiriços da chamada "demarcação" merecem um debate sério, pelo qual se torna descabido enveredar aqui. 
Lembremos, não obstante, e tendo por horizonte a dialéctica que subsiste entre o "absoluto" e o "relativo" na verdade, uma observação que será fecunda para um equacionamento destas questões: "é historicamente condicional qualquer ideologia, mas é incondicional que a qualquer ideologia científica (diferentemente, por exemplo, da ideologia religiosa) corresponde uma verdade objectiva, uma natureza absoluta", Vladímir Ílitch LÉNINE, Materialismo e Empiriocriticismo. Notas críticas sobre uma filosofia reaccionária (1909), II, 5; Lisboa - Moscovo, Edições Avante! - Edições Progresso, 1982, p. 102.

${ }^{24}$ Combatendo as tentações de resvalamento para o formalismo abstracto, afirmava Hegel: “o método é a consciência acerca da forma do automovimento interno do seu conteúdo" -- "die Methode ist das Bewußtsein über die Form der inneren Selbstbewegung ihres Inhalts", HEGEL, Wissenschaft der Logik, Einleitung, Allgemeine Begriff der Logik; TW, vol. 5, p. 49.

Um epistemólogo insuspeito de concescendentes simpatias hegeliano-dialécticas, por sua vez, lembra: "Para levar adiante uma investigação é mister "entrar na matéria", ou seja, apropriar-se de certos conhecimentos, atentar naquilo que se ignora, escolher o que se quer averiguar, planear a maneira de o fazer, etc. O método científico não supre estes conhecimentos, decisões, planos, etc., mas ajuda a ordená-los, a precisá-los, e a enriquecê-los. O método forma, não informa. É uma atitude, mais do que um conjunto de regras para resolver problemas." -- "Para llevar adelante una investigación es menester "entrar en materia", o sea, apropiarse de ciertos conocimientos, advertir qué se ignora, escoger qué se quiere averiguar, planear la manera de hacerlo, etc. El método científico no suple a estos conocimientos, decisiones, planes, etc., sino que ayuda a ordenarlos, precisarlos y enriquecerlos. El método forma, no informa. Es una actitud más que un conjunto de reglas para resolver problemas.", Mario BUNGE, Epistemología. Curso de Actualización (1980), 2, 3; Barcelona - Caracas - México, Editorial Ariel, $1981^{2}$, p. 35 .

${ }^{25}$ Veja-se, por exemplo: Stephen Edelston TOULMIN, Human Understanding. The Collective Use and Evolution of Concepts, Princeton, Princeton University Press, 1972.

Para uma inflexão no sentido de um paradigma pragmático-transcendentalmente argumentado no seio de uma dada comunidade racional de falantes: Karl-Otto APEL, Transformation der Philosophie (1973), Frankfurt am Main, Suhrkamp Verlag, 1976², 2 vols., e Jürgen HABERMAS, Theorie des kommunikativen Handelns (1981), Frankfurt am Main, Suhrkamp Verlag, $1985^{3}, 2$ vols.

${ }^{26}$ Em rigoroso sentido forte, a «ciência» ( $\left.f \mathrm{~B} 4 \Phi \vartheta Z: 0\right)$ é uma «consideração» $\left(\Downarrow_{\mathrm{B}} \overline{8} 0 \mathrm{P} 4 \mathrm{H}\right)$ do «universal» $(6 \forall 2 \overline{8} \cong \Lambda)$ e do necessário, de «aquilo que é por necessidade» $(\vartheta \in f>\square<\varsigma(60 \mathrm{H} \angle<)$; cf. ARISTÓTELES, Ética Nicomaqueia, VI, 6, 1140 b 31 .

No abrandamento de uma formulação mitigada, que entretanto o peso das realidades porventura recomenda, a ciência passa a ser «de aquilo que é sempre, ou a maior parte das vezes» $(\vartheta \cong \neg \square \gamma \mathfrak{R} \angle<\vartheta \cong \mathrm{H} \times\rangle \mathrm{H} f \mathrm{~B} \Re \vartheta \in$ $\mathrm{B} \cong 8 \beta) .$. ; cf. ARISTÓTELES, Metafísica, K, 8, 1065 a 5 .

${ }^{27}$ É neste sentido, designadamente, que «nada impede que haja uma ciência imóvel acerca de coisas móveis» -«nihil prohibet de rebus mobilibus immobilem scientiam habere», TOMÁS DE AQUINO, Summa Theologiae, I, q. 84 , a. 1 , ad 3 .

${ }^{28}$ Lembremos que a ironia platónica em torno das estátuas de Dédalo -- que, ao aparentarem uma ilusão de movimento, funcionavam como emblema da "opinião" $(* \overline{-} \forall)$ fugaz - tinha em vista sublinhar o desejado contraste com a estabilidade requerida pela ciência, cujo objecto, por conseguinte, haveria que ser buscado na permanência da "entidade" ( $\cong \Leftrightarrow \Phi \therefore \forall)$. Cf. PLATÃO, Ménon, 97 c - 98 a.

É interessante verificar como, por exemplo, no século VII, deparamos com uma sedimentação destas perspectivas na abordagem isadoriana da diferença a estabelecer entre scientia e opinatio. Cf. ISIDORO DE SEVILHA, Etymologiarum libri XX, II, 24, 2.

${ }^{29}$ Veja-se, por exemplo, David HUME, An Enquiry concerning Human Understanding (1748), VII, II; ed. Lewis Amherst Selby-Bigge, Oxford, Clarendon Press, 1902², pp. 73-79.

${ }^{30}$ Até porque é in lingua matematica que o grandissimo libro da Natureza está escrito. Cf. Galileo GALILEI, Il Saggiatore (1623), 6; ed. Ferdinando Flora, Torino, Giulio Einaudi editore, $1977^{2}$, p. 33.

${ }^{31}$ Cf. Hans VAIHINGER, Die Philosophie des Als Ob. System der theoretischen, praktischen und religiösen Fiktionen der Menschheit auf Grund eines idealistischen Positivismus (1911), I, A, III; Leipzig, Verlag von Felix Meiner, $1922^{7-8}$, pp. 36-37. 
Porque a inspiração deste modelismo epistémico provém historicamente das áreas da Economia, veja-se: Joseph Alois SCHUMPETER, History of Economic Analysis (1952), III, 5, 5, c; ed. Elizabeth Boody Schumpeter, London - Boston - Sidney, Allen \& Unwin Publishers, $1982^{12}$, pp. 561-570.

${ }^{32}$ Com declinações doutrinárias diversas -- nomeadamente, quanto ao entendimento do "pensar" e do "ser" --,

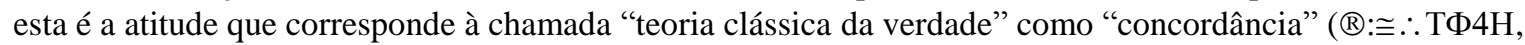
adaequatio, Übereinstimmung) entre o "dito" (ou «mentado») e a "coisa".

Veja-se, por exemplo: ARISTÓTELES, Metafísica, 1, 10, 1051 a 34 - 1051 b 9; TOMÁS DE AQUINO, Quaestiones disputatae de veritate, q. I, a. 1; John LOCKE, An Essay concerning Human Understanding (1690), IV, V, 2 (ed. Alexander Campbell Fraser, reprod. New York, Dover Publications, 1959, vol. II, p. 244); etc. Para outras resignificações da «concordância»: Gottlob FREGE, «Der Gedanke. Eine logische Untersuchung» (1918), Logische Untersuchungen, ed. Günther Patzig, Göttingen, Vandenhoek \& Ruprecht, 1993 ${ }^{4}$, pp. 30-53; Moritz SCHLICK, Allgemeine Erkenntnislehre (1925), I, 10, Frankfurt am Main, Suhrkamp Verlag, 1979², pp. 78-89; Alfred TARSKI, «Die semantische Konzeption der Wahrheit und die Grundlagen der Semantik» (1944), Wahrheitstheorien. Eine Auswahl aus den Diskussionen über Wahrheit im 20. Jahrhundert, ed. Gunnar Skirbekk, Frankfurt am Main, Suhrkamp Verlag, 1980², pp. 140-188.

${ }^{33}$ Lembremos que o emprego cartesiano do critério da "evidência" serve precisamente de respaldo a esta "certeza": "as coisas que nós concebemos muito claramente e muito distintamente são todas verdadeiras" - "les choses que nous concevons fort clairement et fort distinctement sont toutes vraies", René DESCARTES, Discours de la Méthode pour bien conduire sa raison et chercher la vérité dans les sciences (1637), IV; ed. Étienne Gilson, Paris, Librairie Philosophique Jean Vrin, 1966, p. 91.

No fulcro da chamada "filosofia da fé" (Glaubensphilosophie), deparamos com a entronização da "certeza imediata" (unmittelbare Gewißheit), repescada dos fundos da intimidade crente: não só não precisa de, como exclui, quaisquer «razões» (Gründe). Cf., por exemplo, Friedrich Heinrich JACOBI, Über die Lehre des Spinoza in Briefen an den Herrn Moses Mendelssohn (1785); ed. Marion Lauschke, Darmstadt, Wissenschaftliche Buchgesellschaft, 2000, p. 113.

O sinal de partida havia, de alguma maneira, sido entretanto dado por um dito agostiniano, que se veio a tornar fonte para muitas inspirações: "Não vás fora; volta para ti próprio; a verdade habita no homem interior" - "Noli foras ire; in teipsum redi; in interiore homine habitat veritas», AGOSTINHO, De Vera Religione, XXXIX, 72. Neste particular, é significativo que Husserl não deixe de chamar a atenção para a necessidade de se introduzirem "diferenciações" (Differenzierungen) no campo das "evidências" (Evidenzen), com vista à justa qualificação do tipo de "certeza" (Gewißheit) que proporcionam. Cf. HUSSERL, Cartesianische Meditationen. Eine Einleitung in die Phänomenologie (1929), I, § 6; Gesammelte Werke (Husserliana), ed. Hermann Leo Van Breda, Den Haag, Martinus Nijhoff, $1973^{2}$, vol. I, pp. 55-57.

No que se refere à linguagem ordinária, há decerto observações que merecem ponderação: "Não se infere o estado-de-coisas a partir da certeza própria. A certeza é, por assim dizer, um tom [de voz] em que se declara o estado-de-coisas, mas não se infere do tom [de voz] que ele seja justificado." - "Man schließt nicht auf den Tatbestand aus der eigenen Gewißheit. Die Gewißheit ist gleichsam ein Ton, in dem man den Tatbestand feststellt, aber man schließt nicht aus dem Ton darauf, daß er berechtigt ist.", Ludwig WITTGENSTEIN, Über Gewißheit (1949-1951), n. 30; ed. Gertrud Elizabeth Margaret Anscombe e George Henrik von Wright, Oxford, Basil Blackwell, 1974², p. 6.

${ }^{34}$ Cf. HEGEL, Phänomenologie des Geistes (1807), Vorrede; TW, vol. 3, pp. 24-25.

${ }^{35}$ Cf. MARX, Das Kapital. Kritik der politischen Ökonomie. Dritter Band. Hamburg 1894, III, II, VII, 48, III; $\mathrm{MEGA}^{2}$, vol. II/15, p. 792.

${ }^{36}$ A meu ver, este é o enquadramento onto-epistemológico (materialista dialéctico) que sustenta, e em que se processa, toda a crítica de Marx aos posicionamentos da "economia vulgar" (Vulgärökonomie) que, naquele seu afã apologético de "santificar o subsistente" (das Bestehende zu heiligen), ou seja, a ordem estabelecida MARX, Das Kapital. Kritik der politischen Ökonomie. Dritter Band. Hamburg 1894, III, II, VI, 47, II; MEGA², vol. II/15, p. 768 --, não cura de lhe surpreender, e investigar, nem a génese (histórica) que carrega, nem a moldura (ontológica) dos supostos sobre que repousa, nem a dinâmica (prática) das transformações que o desenvolvimento da sua contraditoriedade traz no bojo.

Penso que a esta luz se podem ler muitas passagens conhecidas, como, por exemplo: MARX, Das Kapital. Kritik der politischen Ökonomie. Erster Band. Hamburg 1872, I, I, 1, 3, D, 4 (MEGA ${ }^{2}$, vol. II/6, pp. 111-112), Das Kapital. Kritik der politischen Ökonomie. Dritter Band. Hamburg 1894, III, II, VII, 48, III (MEGA ${ }^{2}$, vol. II/15, pp. 804-806), ou Theorien über den Mehrwert, III, Beilagen, 5 (MEW, vol. 26.3, pp. 489-511).

O cerne da questão encontra-se devidamente identificado. Se, como acontece com "o economista vulgar" (der Vulgärökonom), nos ativermos apenas à "aparência” (ilusória, Schein) das coisas: "Então, para quê ainda uma 
ciência?" -- "Wozu dann überhaupt eine Wissenschaft?”, MARX, Brief an Ludwig Kugelmann 11. Juli 1868; MEW, vol. 32, p. 553.

${ }^{37}$ É esta «razão» que «governa todas as coisas através de todas as coisas» -- «f6 $6 \exists \Xi \Delta<0 \Phi \gamma \mathrm{B} \varsigma<\vartheta \forall * 4 \square$ $\mathrm{B} \varsigma<\vartheta \mathrm{T}<»$, HERACLITO, Fragmento B 41; Die Fragmente der Vorsokratiker, ed. Hermann Diels e Walther Kranz, Berlin, Weidmannsche Verlagsbuchhandlung, 1956 , vol. I, p. 160.

${ }^{38}$ Cf. PLATÃO, República, VII, 534 b.

${ }^{39}$ De entre a bibliografia de referência, e seguindo orientações acentuadamente diferenciadas: Ludwig von BERTALANFFY, General Systems Theory. Foundations, Development, Applications (1968), New York, George Braziller, 1976²; Igor Viktorovich BLAUBERG, Vadim Nikolaevich SADOVSKY, e Erik Grigorievich YUDIN, Systems Theory. Philosophical and Methodological Problems, Moscow, Progress Publishers, 1977; Mario BUNGE, A World of Systems, Dordrecht - Boston, D. Reidel Publishing Company, 1979. Com especial incidência sobre a problemática da sociologia: Talcott PARSONS, The Social System (1951), New York, The Free Press, $1964^{2}$, e Niklas LUHMANN, Soziale Systeme. Grundriß einer allgemeinen Theorie (1984), Frankfurt am Main, Suhrkamp Verlag, 1996 ${ }^{6}$; etc.

${ }^{40}$ Para um conspecto deste tópico no quadro da modernidade filosófica, veja-se, por exemplo: Wladimir A. LEKTORSKY, Das Subjekt-Objekt Problem in der klassischen und modernen bürgerlichen Philosophie, Berlin, Deutscher Verlag der Wissenschaften, 1968.

${ }^{41}$ Esbocemos um rápido apontamento ilustrativo. Sem dúvida que o físico Mach manifesta a pretensão de instaurar um fundamento real para a ciência que cultiva. No entanto, do ponto de vista onto-gnosiológico, Mach permanece enredado nas tramas do idealismo, nomeadamente, ao promover a dissolção principial da materialidade do ser no complexo de elementos que as sensações proporcionam. Cf. Ernst MACH, Die Analyse der Empfindungen und das Verhältnis des Physischen zum Psychischen (1883, 1922'), ed. Gereon Wolters, Darmstadt, Wissenschaftliche Buchgesellschaft, 1991.

${ }^{42}$ Uma ponderação séria deste ponto é imprescindível, porque não tem forçosamente que ir aterrar na plataforma cómoda da discriminação oitocentista entre "ciências da Natureza" (Naturwissenschaften) e "ciências do espírito" (Geisteswissenschaften) - cf., por exemplo, Wilhelm DILTHEY, Einleitung in die Geisteswissenschaften. Versuch einer Grundlegung für das Studium der Gesellschaft und der Geschichte (1883), I, II; Gesammelte Schriften, ed. Georg Misch, Leipzig - Berlin, Verlag von B. G. Teubner, 1923², vol. I, pp. 4-14--, que parte de, e virá a servir como rampa de lançamento para, toda uma frequentada série de contraposições metafísicas, designadamente, entre "ser" e "valor".

${ }^{43}$ Um esclarecido entendimento da dimensão histórica da ciência conduz a que ela não mais possa ser vista como um mero processo de acumulação linear. É nesta perspectiva que penso ser de considerar, por exemplo: Thomas Samuel KUHN, The Structure of Scientific Revolutions (1962), Chicago - London, The University of Chicago Press, $1970^{2}$.

Os alertas contra as deslumbradas precipitações de um certo «cientismo positivista» vinham, no entanto, bem mais de trás. Lembremos, a título de quase aleatória ilustração (bem humorada), um deles:

"Recusar-se a examinar e a estudar as opiniões dos cientistas dos tempos passados, pela razão de que houve um tempo em que elas eram supersticiosamente veneradas como tendo um valor superior a qualquer experiência e demonstração, é tão irrazoável como se um astrónomo recusasse observar o curso dos astros, ou um naturalista rejeitasse ocupar-se dos hábitos das aves, simplesmente porque os sacerdotes babilónios, ou os áugures etruscos, pretendiam desumir da posição dos astros, ou do humor das galinhas, presságios infalíveis acerca do andamento dos acontecimentos humanos." - "il ricusarsi d'esaminare e studiare le opinioni degli scienziati dei tempi trascorsi per la ragione che vi fu un tempo in cui esse erano superstiziosamente venerate come aventi valore superiore a ogni esperienza e dimostrazione, è tanto irragionevole come se un astronomo ricusasse di osservare il corso degli astri o un naturalista rifiutasse di occuparsi delle abitudini degli uccelli, semplicemente perché i sacerdoti babilonesi o gli auguri etruschi pretendevano desumere, dalla posizione degli astri o dall'umore delle galline, presagi infallibili sull'andamento degli eventi umani.", Giovanni VAILATI, Sull'importanza delle ricerche relative alla storia delle scienze (1897); Il metodo della filosofia. Saggi di critica del linguaggio, ed. Ferruccio Rossi-Landi, Bari, Giuseppe Laterza \& Figli, 1967², p. 44.

\footnotetext{
${ }^{44}$ Para uma conhecida apologia do princípio do "vale tudo" (anything goes), em ambiente de anarquismo metodológico magnificado: Paul FEYERABEND, Against Method. Outline of an anarchistic theory of knowledge (1975), London - New York, Verso, $1993^{3}$
} 


\begin{abstract}
${ }^{45}$ Nos termos do idealismo hegeliano, «o solo do pensamento» (das Boden des Gedankens) constitui «o campo científico» (das wissenschafliche Feld). Cf. HEGEL, Vorlesungen über die Beweise vom Dasein Gottes (1829), 8; TW, vol. 17, p. 402.

O comentário crítico de Feuerbach, no que se refere a esta principial dissolução hegeliana do ser num «pensado», é certeiro: "Hegel é um pensador que se desfaz em pensar - ele quer agarrar a própria coisa, mas no pensamento da coisa, [quer] estar fora do pensar, mas no próprio pensar --, daí a dificuldade de apreender o conceito 'concreto'." -- "Hegel ist ein sich im Denken überbietender Denker - er will das Ding selbst ergreifen, aber im Gedanken des Dings, außer dem Denken sein, aber im Denken selbst - daher die Schwierigkeit, den 'konkreten' Begriff zu fassen.", Ludwig FEUERBACH, Grundsätze der Philosophie der Zukunft (1843), § 30; Gesammelte Werke, ed. Werner Schuffenhauer, Berlin, Akademie-Verlag, 1982², vol. 9, pp. 313-314.
\end{abstract}

${ }^{46}$ É o ponto de vista adoptado, entre outras orientações, pela "ideologia" (idéologie), entendida, na sua primeira versão francesa, como "a ciência das idéias" (la science des idées), que há-de estar na base de todo o edifício do conhecimento. Pretende falar-se das "coisas" (choses), mas é sempre a "imagem" (image) delas que se torna objecto de escrutínio, porque «os factos estão em nós» (les faits sont en nous). Cf. Antoine-Louis-Claude DESTUTT DE TRACY, Éléments d'Idéologie $\left(1817^{3}\right)$, I, Introduction, c. I, e c. 16; ed. Henri Gouhier, Paris, Librairie Philosophique Jean Vrin, 1970, vol. I, respectivamente, pp. 1-21, 21-28, e 302-354. Não estranha que, neste quadro, haja sido recuperada a tese de que "uma ciência bem tratada não é senão uma língua bem feita" "une science bien traitée n'est qu'une langue bien faite", Étienne Bonnot de CONDILLAC, Traité des Systèmes (1749), XVIII; Oeuvres Philosophiques, ed. Georges Le Roy, Paris, Presses Universitaires de France, 1947, vol. I, p. 216.

${ }^{47}$ Diga-se na passada que esta é, porventura, a grande lição que podemos extrair desde o arranque do programa, numas florescentes colónias gregas da Ásia Menor, uns vinte e seis séculos atrás.

Cf. Benjamin FARRINGTON, Science in Antiquity (1936), London - New York, Oxford University Press, $1969^{2}$, e Greek Science (1944 e 1949), London, Pelican Books, $1953^{2}$. De entre a vasta bibliografia sobre a ciência na Antiguidade, vejam-se igualmente: Léon ROBIN, La pensée grecque et les origines de l'esprit scientifique, Paris, Albin Michel, n. ed. 1973; Geoffrey Ernest Richard LLOYD, Early Greek Science: Thales to Aristotle, London New York, Chatto \& Windus - W. W. Norton \& Co., 1970, e Kurt von FRITZ, Grundprobleme der Geschichte der antiken Wissenschaft, Berlin - New York, Walter de Gruyter \& Co., 1971.

${ }^{48} \mathrm{O}$ cultivo científico dos saberes pode decerto assumir contornos, e processar o seu desenvolvimento em estádios, muito diversos. É aquilo que, na realidade, historicamente aconteceu e acontece. No passado, e à nossa volta. No entanto, do ponto de vista estratégico, apesar de todas as dificuldades e de todos os obstáculos, torna-se decisivo, até para que as situações menos favoráveis venham a ser convenientemente superadas, que a faina nesse cultivo constitua ocupação central numa Universidade. Restringindo-se ao mero ensino de aquilo que aprendeu, o professor abdica da sua condição de agente activo na cultura do saber. Não é o nome exibido nas tabuletas, ou a classificação etária dos alunos, que, pelo encanto de um decreto, chama à vida uma Universidade. É a qualidade que ela não desiste de pôr no seu trabalho.

${ }^{49} \mathrm{Na}$ verdade da sua realidade primeira, é ontológica. Porque os problemas giram sempre em torno do cuidado posto - pelos indivíduos, pelos grupos, pelas comunidades -- na tomada a cargo do ser que, na sua deveniência histórica, integramos e vamos modelando.

Recebido: jul/2015 Aprovado: $\quad$ ago/2015 